\title{
Indomethacin and Naproxen suppositories in the treatment of rheumatoid arthritis
}

\author{
H. BERRY, D. SWINSON, J. JONES, AND E. B. D. HAMILTON
}

From the Departments of Rheumatology, King's College Hospital and the Wrightington Hospital, Lancashire⿻

SUMMARY A double-blind cross-over study of 35 out-patients with rheumatoid arthritis showed $\overrightarrow{\vec{\omega}}$ that Naproxen and Indomethacin suppositories were both effective forms of treatment in rheumatoid arthritis, both being significantly superior to placebo in terms of relief of morning stiffness.

Indomethacin is a drug used widely in rheumatological practice. The oral dose employed is variable, but previous studies have suggested that one $100 \mathrm{mg}$ suppository is as effective as $100 \mathrm{mg}$ of capsules in relief of early morning stiffness in the treatment of rheumatoid arthritis.

More recently Naproxen tablets have been introduced as an analgesic, anti-inflammatory compound in the treatment of rheumatoid arthritis. At a dose of $500 \mathrm{mg}$ it has been suggested that, of the available proprionic acid derivatives, it is a drug of choice judged by patient preference. It produced the least number of unwanted effects compared with other drugs of this group (Huskisson et al., 1976).

The results of a comparative trial between Indomethacin, Naproxen, and placebo suppositories are reported.

\section{Material and methods}

\section{TRIAL DESIGN}

Out-patients with rheumatoid arthritis were admitted to the trial at both King's College Hospital, London and Wrightington Hospital, Lancashire. The trial was three-way, double-blind, and of crossover design. The suppositories contained Naproxen $500 \mathrm{mg}$ or Indomethacin $100 \mathrm{mg}$ or inactive placebo. The trial period was 3 weeks on each treatment. The suppositories were all the same colour and the placebo suppositories matched the Indomethacin suppositories; the Naproxen suppositories whilst they were of the same colour and design were slightly larger. Treatment was allocated randomly using all 6 possible orders of administration. During the trial, patients were allowed up to $3 \mathrm{~g}$ per day of Paracetamol as an escape drug. All other nonsteroidal anti-inflammatory drugs were stopped 1 week before the start of the trial. Patients ond stabilised dosage of penicillamine, gold, or corti-o costeroids were included in the study.

The efficacy of treatment was assessed initially $\vec{D}$ and then at the end of each trial period by means of (1) Pain using the $10 \mathrm{~cm}$ visual analogue scale, $\frac{c}{\infty}$ range 'no pain' to 'worst ever pain' (Berry and Huskisson, 1972). (2) Early morning stiffness $e^{\circ}$ recorded in minutes. (3) Articular index using the. method of Ritchie et al. (1968). (4) Ring size of theO proximal interphalangeal joints. (5) Patient prefer-乏े ence for the 3 treatments. (6) Doctor preference for the 3 treatments. (7) Blood levels were also measured in order to ascertain the absorption of Naproxen.

UNWANTED EFFECTS

These were elicited in 3 different groups. Proctoscopy: the results of this were recorded as normal, ulceration, erosion, oedema, erythema, or bleeding. Rectal symptoms were elicited by asking whether the patient had had any rectal problems. Different side effects were elicited by means of simple indirect question, 'Has the treatment upsetô you in any way?'.

\section{Results}

A total of 35 patients were admitted to the study, 11 male and, 24 female. All had erosive rheumatoid.o arthritis and 29 of the patients were sero-positive, $N$ 13 patients received no other therapy, 11 were taking penicillamine, 9 gold salts and 4 corticosteroids.

CLINICAL RESULTS

Pain measured on a $10 \mathrm{~cm}$ visual analogue scale $\square$ was reduced by all 3 treatments. For Naproxen $\bar{\sigma}$ and Indomethacin the change was statistically significant at the $\mathbf{P}<0.05$ level. Both active $\frac{\mathbb{\Phi}}{Q}$ 
suppositories were superior to placebo. This reached significance in favour of Indomethacin $(P<0.05)$ but not Naproxen. There was no statistical difference between the active drugs.

Morning stiffness was significantly reduced by Naproxen $(P<0.03)$ and by Indomethacin $(P<0.01)$ but not by placebo. Both Naproxen and Indomethacin were significantly better than placebo in reducing morning stiffness $(P<0.05)$.

Improvement in articular index was seen with both drugs but not with placebo. However, only the change on Indomethacin was significantly superior to placebo $(\mathrm{P}<0 \cdot 02)$.

The difference between the active preparations was not significant. Ring size was reduced by all 3 treatments with no difference between their effects. (Table 1).

\section{BLOOD LEVELS}

Blood was taken from 29 patients for assessment of Naproxen levels. One patient showed no demonstrable Naproxen in his blood (he showed preference for placebo at the end of the trial!). The range of levels was from $5 \cdot 2$ to $78 \cdot 6 \mu \mathrm{g} / \mathrm{ml}$ of Naproxen. The mean was $32 \cdot 7 \mu \mathrm{g} / \mathrm{ml}$.

\section{BOWEL HABIT}

No change occurred during the study either in the frequency of bowel action or stool formation on any treatment.

Table 1 Clinical change (statistics based on Student's t test)

\begin{tabular}{|c|c|c|c|c|c|}
\hline \multirow[t]{2}{*}{ Pain } & & \multirow{2}{*}{$\begin{array}{l}\text { Morning } \\
\text { stiffness } \\
\text { (min) }\end{array}$} & \multirow{2}{*}{$\begin{array}{l}\text { Articular } \\
\text { index }\end{array}$} & \multicolumn{2}{|c|}{ Ring size } \\
\hline & & & & Left & Right \\
\hline Base & $5 \cdot 7$ & 170 & $14 \cdot 3$ & 558 & 572 \\
\hline \multicolumn{6}{|c|}{ Changes } \\
\hline I & $-1 \cdot 7$ & -77 & $-2 \cdot 2$ & 9 & 8 \\
\hline $\mathbf{N}$ & $-1 \cdot 4$ & -53 & $-1 \cdot 6$ & 9 & 8 \\
\hline $\mathbf{P}$ & -0.6 & -12 & $+0 \cdot 1$ & 9 & 8 \\
\hline \multicolumn{6}{|l|}{ Statistics } \\
\hline N \&I & NS & NS & NS & NS & NS \\
\hline $\mathbf{N} \& \mathbf{P}$ & $P<0.08$ & $P<0.05$ & NS & NS & NS \\
\hline I \&P & $\mathbf{P}<0.05$ & $P<0.05$ & $P<0.05$ & NS & NS \\
\hline
\end{tabular}

$\mathrm{I}=$ Indomethacin. $\quad \mathrm{N}=$ Naproxen. $\quad \mathrm{P}=$ placebo

Table 2 Rectal side effects

\begin{tabular}{lccc}
\hline & $I$ & $P$ & $N$ \\
\hline Rectal discomfort & 7 & 6 & 2 \\
Rectal bleeding & 3 & 1 & 1 \\
Soreness & 0 & 1 & 2 \\
Tenesmus & 1 & 0 & 1 \\
Flatus & 2 & 0 & 1 \\
Total & 13 & 8 & 7 \\
\hline
\end{tabular}

\section{SIDE EFFECTS}

\section{Rectal}

Less rectal side effects were reported from Naproxen than any other treatment, but this did not reach significance (Table 2). The results from proctoscopy are listed in Table 3. No ulceration or erosion occurred during the trial. However, oedema and erythema occurred frequently on the test drugs. Table 4 lists the general side effects. Rashes and gastro-intestinal side effects occurred with greater frequency on placebo, than with either active drug. There was marked discrepancy between the two centres in terms of the number of side effects reported (many more at Wrightington than at King's), but the actual number of patients developing side effects was similar.

\section{WITHDRAWALS}

Four patients discontinued therapy during the course of the study. Three had pain during the placebo period and the third had an unrelated admission to hospital.

\section{PATIENT AND OBSERVER PREFERENCE}

The physicians favoured Indomethacin (14 times), Naproxen (12 times), and placebo (5 times). The patients' preference was for Indomethacin (12), Naproxen (11), placebo (6), and no difference twice. There was no significant difference between these results.

Table 3 Incidence of side effects observed on proctoscopy

\begin{tabular}{llll}
\hline & $I$ & $P$ & $N$ \\
\hline Oedema & 2 & 3 & 3 \\
Erthema & 7 & 4 & 8 \\
Erythema and bleeding & 1 & 1 & 1 \\
\hline
\end{tabular}

Table 4 General side effects

\begin{tabular}{lccc}
\hline & $I$ & $P$ & $N$ \\
\hline Nausea & 4 & 5 & 1 \\
Vomiting & 2 & 2 & 0 \\
Indigestion & 3 & 5 & 3 \\
Constipation & 1 & 3 & 4 \\
Tinnitus & 1 & 4 & 2 \\
Vertigo & 2 & 3 & 4 \\
Headache & 4 & 2 & 1 \\
Rash & 1 & 6 & 4 \\
Oedema & 1 & 1 & 4 \\
Total & 19 & 31 & 23 \\
\hline
\end{tabular}




\section{Discussion}

In this study a new preparation of Naproxen used as suppositories has been shown to be more effective than placebo and as effective as Indomethacin suppositories. This is judged by reduction of early morning stiffness. Pain relief favoured Indomethacin. In terms of patient preference the two drugs appeared to be very similar.

There is a group of patients who prefer suppositories to capsules and Naproxen suppositories would seem to offer an alternative treatment to Indomethacin suppositories. It would appear to have advantage over that drug in terms of side effects but slightly lower efficacy. Patient preference was similar for the two drugs. It may be seen as ac useful alternative treatment.

\section{References}

Berry, H., and Huskisson, E. C. (1972). A trial of methoprixol. Clinical Trial Journal, 9, 13.

Huskisson, E. C., Woolf, D. L., Balme, H. W., Scott, J. and Franklyn, S. (1976). Four new anti-inflammatory drugs: responses and variations. British Medical Journal

Ritchie, D. M., Doyle, J. A., McInnes, J. M., Jasani, M. K. Dalakos, T. G., Grievson, P., and Buchanan, W. W. (1968): Clinical studies with an articular index for the assessment of joint tenderness in patients with rheumatoid arthritis Quarterly Journal of Medicine, 37, 393. 